\title{
Role of the vomeronasal organ and prolactin in the acceleration of puberty in female mice
}

\author{
D. E. Lomas and E. B. Keverne \\ Department of Anatomy, University of Cambridge, Downing Street, Cambridge CB2 3DY, U.K.
}

\begin{abstract}
Summary. Young female mice were grouped on Day 21 after birth and subjected to removal of the vomeronasal organ. Soiled bedding from intact adult males failed to advance the onset of first oestrus in these lesioned mice compared to the various control groups. Vomeronasal organ lesions of prepubertal females also prevented increases in uterine weight following exposure to soiled bedding for $48 \mathrm{~h}$ on Day 23 when compared to controls. Lowering prolactin by injections of bromocriptine for 48 $\mathrm{h}$ on Day 26, but not Day 23, advanced the onset of puberty in intact and vomeronasal organ-lesioned females. Elevating prolactin by injections of domperidone were without effect on the early onset of oestrus when compared to sham-injected controls. It is concluded that marked similarities exist in both the receptor system and neuroendocrine mechanism of male pheromone action observed in prepubertal females and that seen in the adult.
\end{abstract}

\section{Introduction}

The reproductive biology of the female mouse is strongly influenced by pheromones, both in the adult and before puberty. Chemical cues in the urine of both sexes affect development of the reproductive system in females, male urine accelerating the onset of first oestrus (Vandenbergh, 1969) and urine from other females delaying the onset of first oestrus (Cowley \& Wise, 1972; Vandenbergh, 1973). Male mouse urine applied to the oral nasal groove of prepubertal female mice brings forward the onset of first oestrus by 4-6 days relative to those similarly treated with water (Vandenbergh, 1969). Exposure to male urine appears not to influence the timing of vaginal opening, but does influence the onset of first oestrus suggesting that pheromones do not trigger puberty, but accelerate the process of sexual maturation (Colby \& Vandenbergh, 1974). One of the earliest physical consequences of exposing prepubertal females to male pheromones is a rapid increase in uterine weight within the first $24 \mathrm{~h}$ of exposure (Bronson \& Maruniak, 1976; Wilson, Beamer \& Whitten, 1980).

The receptor system for male mouse urinary pheromones has been identified in the adult as the vomeronasal organ (Reynolds \& Keverne, 1979; Bellringer, Pratt \& Keverne, 1980), and there is evidence that this system may also be involved in the acceleration of puberty (Kaneko, Debski, Wilson \& Whitten, 1980). The neuroendocrine mechanism of action following urine exposure has also been investigated in adult mice, particularly in relation to the effects on LH (Bronson \& Desjardins, 1974; Wilson et al., 1980) and prolactin (Bruce \& Parkes, 1960; Keverne, 1979; Milligan, 1980). Direct measurements of prolactin and LH in the adult mouse have not resolved this issue since both these hormones change, LH increasing and prolactin decreasing following exposure to male urine (Bronson, 1976). However, the hormonal changes in serial blood samples from adult female mice exposed to males would suggest that changes in 
prolactin precede changes in $\mathrm{LH}$ release (Ryan \& Schwartz, 1980). If, as originally suggested by Vandenbergh (1973), one pheromone induces synchrony of oestrus, pregnancy blockage and accelerated sexual maturation, then one might predict not only the involvement of the same neural pathways but similar neuroendocrine mechanisms. The neuroendocrine events stimulated in prepubertal females by exposure to males suggest increases in both $\mathrm{LH}$ and prolactin (Bronson \& Maruniak, 1976) and prolactin is thought to be high and LH low during the prepubertal period (Ojeda, Advis \& Andrews, 1980). Wuttke, Honma, Lamberts \& Hohn (1980) have suggested that high prolactin in the prepubertal period increases LH receptor sites on the granulosa cells and at the same time prevents LHRH release from the hypothalamus by increasing dopamine turnover. Therefore, providing sufficient time has elapsed to allow maturation of the ovary, a lowering of prolactin concentration might accelerate the onset of puberty.

The purpose of this study was to examine the role of the vomeronasal system in the early onset of puberty by pheromone exposure, together with manipulations of prolactin using the dopamine agonist bromocriptine and the dopamine antagonist domperidone.

\section{Materials and Methods}

\section{Animals}

Young female CFLP mice reared in the absence of males were weaned on Day 21 and housed in groups of $6-9$ animals in plastic cages $\left(35.5 \times 8 \times 21 \mathrm{~cm}^{3}\right)$ with wood shaving as bedding. The lighting $(12 \mathrm{~h}$ light $(06: 00-18: 00 \mathrm{~h}) / 24 \mathrm{~h})$ and temperature $\left(20 \pm 1^{\circ} \mathrm{C}\right)$ were controlled. Soiled bedding from Balb C adult males was added to the cages on Day 23 and was renewed daily until all mice had experienced first oestrus.

Daily examinations were made for vaginal opening after which vaginal smears were taken daily at $10: 00 \mathrm{~h}$ and oestrus was identified by a smear containing a pure population of enucleate cornified cells. The data were subjected to Kruskal-Wallis tests for significance of changes. Mice were weighed on Days 36, 48 and at the onset of oestrus to determine if body weight was influenced by surgical procedures and if this was in any way causally related to time of puberty onset. Analysis of variance was performed on body weights.

\section{Excision of the vomeronasal organ}

The mice were injected intraperitoneally with tribromoethanol (Avertin: $0.02 \mathrm{ml} / \mathrm{g}$ body weight) and placed supine in an adapted small-animal stereotaxic holder. The lower jaw was retracted and small, bilateral incisions (about $1 \mathrm{~mm}$ long) were made in the palate 3-4 mm posterior to the upper incisor teeth. This exposed bilaterally the paramedial Jacobson's cartilages enclosing the vomeronasal epithelium. Using a diathermic cutting tool, the entire organ on each side was cut and burnt away. The resulting gap in the upper palate was filled with polycyanoacrylate tissue cement (Simplex: Howmedica International) and the animals were allowed to recover under observation in a warm place. Histological examination of sagittal head sections confirmed that the vomeronasal organ had been completely destroyed. Sham operations included the anaesthesia, incisions and diathermic cutting of the lower jaw in the midline.

\section{Experiment 1}

Young female mice were allocated to 5 different groups on Day 21 after birth. Group A contained 8 mice which served as controls and were neither lesioned nor exposed to soiled bedding. Group B contained 9 mice exposed on Day 23 to soiled bedding which was renewed daily until first oestrus. Group C contained 7 mice which were exposed to soiled male bedding 
from Day 23 onwards but had received vomeronasal organ lesions on Day 21. Group D contained 6 mice that had received vomeronasal organ lesions on Day 21 but were not subsequently exposed to male bedding. Group E contained 8 mice that were given sham operations and exposed to male bedding from Day 23 onwards.

\section{Experiment 2}

Young female mice were allocated to 5 different groups on Day 21 after birth. A control group, $\mathrm{F}$, received sham injections of vehicle (saline; $0.154 \mathrm{M}-\mathrm{NaCl}$ ). Group $\mathrm{G}$ contained 8 mice which received injections of bromocriptine (Sandoz Ltd) $(125 \mu \mathrm{g} / \mathrm{kg}$ ) starting on Day 23. A dose of $1.25 \mu \mathrm{g}$ bromocriptine in $0.1 \mathrm{ml}$ vehicle was given on Days 23 and 24 in two daily injections at 11:00 and 18:00 h. Group $\mathrm{H}$ contained 9 mice which received injections of bromocriptine starting on Day 26. A dose of $1.25 \mu \mathrm{g}$ in $0.1 \mu \mathrm{l}$ vehicle was given in 3 daily injections at 08:30, 15:30 and 22:30 h on Days 26, 27 and 28. Group I contained 6 mice that had received vomeronasal organ lesions on Day 21 and were given bromocriptine injections starting on Day 26. A dose of $1.25 \mu \mathrm{g}$ in $0.1 \mathrm{ml}$ vehicle was given in 3 daily injections at 08:30, 15:30 and 23:30 h on Days 26, 27 and 28. Group $J$ consisted of female mice that received injections of domperidone (Jansen Pharmaceuticals) $\left(1 \mathrm{mg} \mathrm{kg}^{-1}\right)$ : dose of $0.1 \mathrm{mg}$ in $0.1 \mathrm{ml}$ vehicle (saline) was given in 3 daily injections at 08:30, 15:30 and 22:30 h on Days 26, 27 and 28.

\section{Experiment 3}

Young female mice were allocated to three different groups on Day 21 after birth. Group K contained 8 mice that were exposed to soiled bedding for $48 \mathrm{~h}$, starting on Day 23 after birth. Group $\mathrm{L}$ also contained $8 \mathrm{mice}$ that had received vomeronasal organ lesions on Day 21 and were exposed to soiled bedding from males for $48 \mathrm{~h}$ starting on Day 23. Group $\mathrm{M}$ contained 8 female mice which were not exposed to male bedding and did not receive vomeronasal lesions.

All mice were killed on Day 25 and weighed. The uteri and ovaries were then carefully removed and surrounding fat dissected away before weighing.

\section{Experiment 1}

\section{Results}

As shown in Table 1, urine exposure and vomeronasal organ lesions produced significant effects on the timing of first oestrus. Female mice that were grouped and exposed to male bedding (Group B) were the first to come into oestrus together with sham-operated animals (Group E). Oestrus appeared significantly earlier than in female mice not exposed to male bedding (Group A). Sham-operated and urine-exposed females also came into oestrus sooner than vomeronasal-lesioned mice (Group D), regardless of whether or not the latter were exposed to male bedding (Group C). There was no significant difference in the timing of onset of first oestrus in Groups $\mathrm{C}$ and $\mathrm{D}$ but these two groups of vomeronasal-lesioned mice exhibited oestrus later than did the controls.

There was no significant difference in body weight between any of the five groups on the day of first oestrus (Table 1) or between mice in Groups C and D on Day 44 and those in Group A. There were no significant differences in body weight on Day 44 of mice which had not experienced oestrus compared with those that had come into oestrus earlier (data not shown).

\section{Experiment 2}

As can be seen in Table 1, injection of bromocriptine accelerated the onset of first oestrus in mice injected on Day 26 (Group H), but not on Day 23 (Group G). Even with vomeronasal 


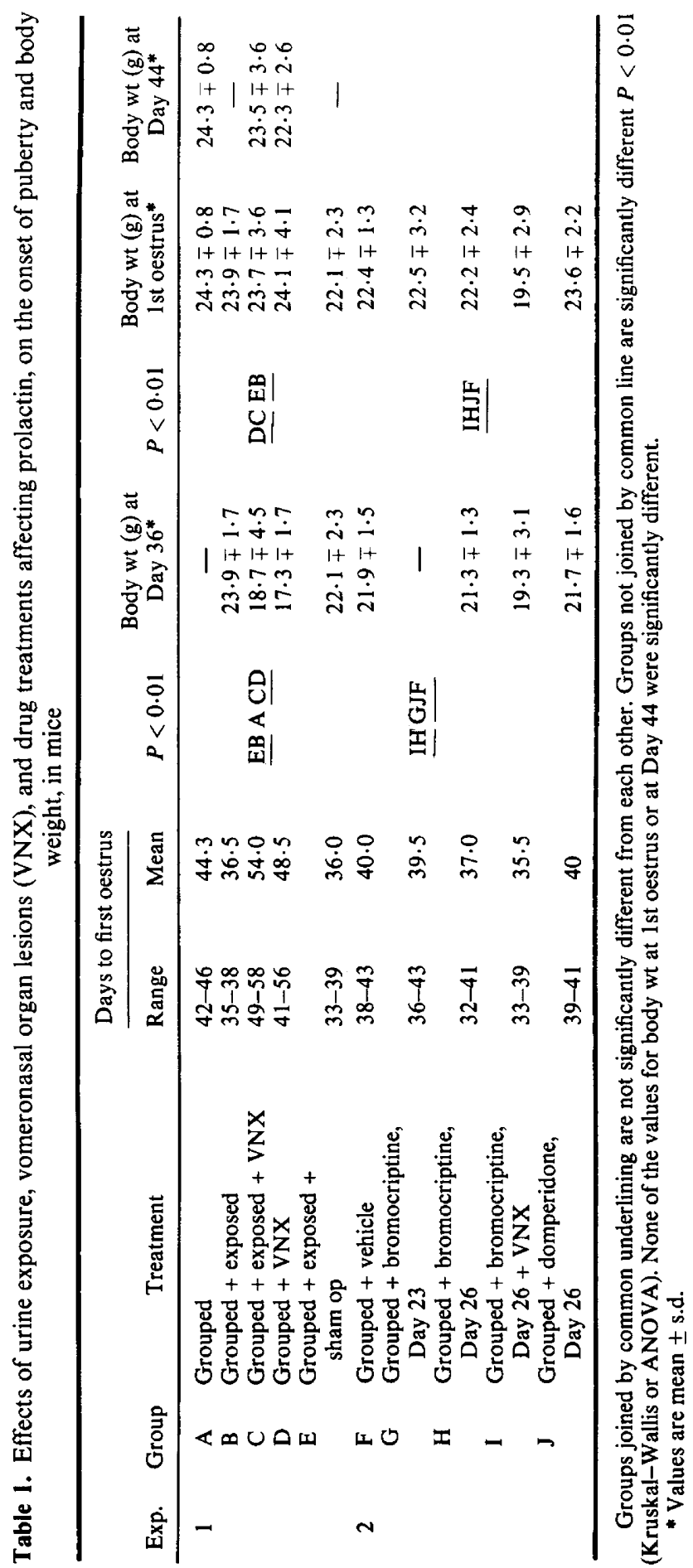


organ lesions, injections of bromocriptine starting on Day 26 induced an early onset of oestrus (Group I) compared to sham-injected animals (Group J) and compared to lesioned animals receiving no drug (Group D). Injection of domperidone (Group J) was without effect on the timing of first oestrus compared to sham-injected controls (Group F). However, sham-injected mice showed a significantly $(P<0.01)$ earlier oestrus than did mice which received no injections (Group A).

There were no significant differences in body weight between the groups on Day 36 or on the day of first oestrus.

\section{Experiment 3}

The uterine-ovarian weight relative to $100 \mathrm{~g}$ body weight (mean \pm s.d.) increased significantly $(P<0.01)$ in mice exposed to soiled bedding for $48 \mathrm{~h}(316 \pm 4.7 \mathrm{mg})$, but not in the group which had received vomeronasal organ lesions $(224 \pm 87 \mathrm{mg})$. Values in lesioned animals were not, however, significantly different from those in mice that had not been exposed to male urine $(220 \pm 59 \mathrm{mg})$.

\section{Discussion}

The onset of first vaginal oestrus in young female mice exposed to urine-soiled bedding from adult males was brought forward by approximately 7 days, a finding very much in line with previously published results (Vandenbergh, 1969; Cowley \& Wise, 1972; Colby \& Vandenbergh, 1974). Vomeronasal organ lesions prevented this effect on the early onset of puberty, both in the short term (increased ovarian-uterine weight in $48 \mathrm{~h}$ ) and in the long term (early onset of first oestrus), suggesting that the receptors for male pheromones are located here rather than in the main olfactory system. This finding adds to and supports the conclusions of a study in which unilateral bulbectomy together with vomeronasal nerve sections also prevented pheromonal acceleration of puberty (Kaneko et al., 1980). However, lesions to the vomeronasal organs in the present study also delayed the onset of puberty beyond that of grouped female mice not exposed to soiled bedding. Removal of the vomeronasal pathways may, therefore, not only deprive the animal of sensory cues, but may itself have a tonic neural influence on developing neuroendocrine mechanisms at the time of puberty. This effect was not reported by Kaneko et al. (1980) who were considering only the short-term effects of urine exposure on uterine weight.

Vomeronasal organ lesions may have affected feeding since the body weight of these mice was significantly lower than that of sham-operated animals at the time sham-operated animals came into oestrus (Day 36). However, differences in body weight have been ruled out as a possible contributory factor in pheromonal influences on puberty (Colby \& Vandenbergh, 1974). It is also unlikely that these differences in body weight were delaying oestrus in vomeronasal-lesioned mice, since on Day 44 they were not different in body weight from controls or any other group that had also come into oestrus.

The neuroendocrine mechanism which determines the onset of puberty in rodents has received a great deal of attention, although not necessarily in the context of pheromone acceleration. Bronson \& Maruniak (1976) have shown that exposure of immature females to a male causes a rapid increase in LH secretion $(0.6 \mathrm{~h})$ which stimulates marked increases in oestradiol lasting about $21 \mathrm{~h}$. This early secretion of $\mathrm{LH}$ and oestradiol was suggested as the trigger of events leading to ovulation, but attempts to induce early puberty by subovulatory doses of LH were unsuccessful. Several reports have implicated prolactin in the regulation of puberty, although opinions are divided as to whether its role is stimulatory (Advis \& Ojeda, 1978; Ojeda et al., 1980) or inhibitory (Wuttke, Dohler \& Gelato, 1976). In the context of male pheromone influences on reproduction in adult female mice it has also been suggested that these 
effects are mediated via prolactin (Bellringer et al., 1980; Ryan \& Schwartz, 1980). The studies reported here further implicate prolactin in the pheromonal acceleration of puberty. Injections of the dopamine agonist, bromocriptine, starting on Day 26 and lasting for $48 \mathrm{~h}$ (equivalent to urine exposure) significantly accelerated the onset of first oestrus compared to sham-injected controls. Onset of first oestrus was also recorded early in vomeronasal-lesioned mice given bromocriptine, especially when compared to vomeronasal-lesioned mice not receiving the drug. Elevating prolactin secretion by domperidone injections did not delay the onset of puberty and female mice exhibited their first oestrus on mean Day 40 , which was no different from sham-injected controls.

Although domperidone injections did not accelerate the onset of oestrus when compared with sham-injected controls, both these groups exhibited their first vaginal oestrus earlier than did females that were untreated. One cannot exclude, therefore, effects of elevated prolactin, induced either by injection stress or the dopamine antagonist, domperidone, on acceleration of puberty. Such paradoxical actions of prolactin on the timing of puberty have tentatively received explanation (Wuttke et al., 1980). High levels of prolactin are initially required to promote development of LH receptors on the granulosa cells. Elevating prolactin at this stage would therefore promote early maturation of the ovary and first oestrus, while lowering prolactin, as occurred with the earlier injections of bromocriptine (Day 23), would not be expected to accelerate first oestrus because the ovary is immature. One consequence of elevated prolactin in the early stages of puberty would be to stimulate hypothalamic dopamine turnover, thereby inhibiting LHRH release. Bromocriptine given after Day 26 would release the LHRH neurones from dopamine inhibition, and providing high levels of prolactin have had sufficient time to act on the ovary then oestrus would ensue. Whatever the explanation, these results strongly implicate prolactin in the timing of the onset of puberty.

Among the primer pheromone effects demonstrated to be transmitted by the vomeronasal accessory olfactory system, we can now include the acceleration of puberty. Moreover, a common neuroendocrine mechanism implicating prolactin can also account for all the primer pheromone effects so far described, the differences being the time of life and reproductive status when exposure to pheromones occurs. Hence, if the site of action and mechanism of action are the same for the different primer pheromone effects, then the need to propose a number of different pheromones to account for these effects becomes redundant. All that is required is a pheromone that communicates maleness, and a pheromone that communicates femaleness.

We thank the Anatomy Department, University of Cambridge for supporting this research; Sue Currie for typing the manuscript; Sandoz Pharmaceuticals Ltd for bromocriptine and Jansen Pharmaceuticals Ltd for domperidone.

\section{References}

Advis, J.P. \& Ojeda, S.R. (1978) Hyperprolactinemia induced precocious puberty in the female rat. Endocrinology 103, 924-935.

Bellringer, J.F., Pratt, H.P.M. \& Keverne, E.B. (1980) Involvement of the vomeronasal organ and prolactin in pheromonal induction of delayed implantation in mice. J. Reprod. Fert. 59, 223-228.

Bronson, F.H. (1976) Serum FSH, LH and prolactin in adult ovariectomised mice bearing silastic implants of estradiol: responses to social cues. Biol. Reprod. 15, $147-152$.

Bronson, F.H. \& Desjardins, C. (1974) Circulating concentrations of FSH, LH and oestradiol and progesterone associated with acute, male induced puberty in female mice. Endocrinology 94, 548-558.
Bronson, F.H. \& Maruniak, J.A. (1976) Differential effects of male stimuli on FSH, LH and prolactin secretion in pre-pubertal female mice. Endocrinology 98, 1101-1108.

Bruce, H.M. \& Parkes, A.S. (1960) Hormonal factors in exteroceptive block to pregnancy in mice. J. Endocr. 20, xxix-xxx.

Colby, D.R. \& Vandenbergh, J.G. (1974) Regulatory effects of urinary pheromones on puberty in the mouse. Biol. Reprod. 11, 268-279.

Cowley, J.J. \& Wise, D.R. (1972) Some effects of mouse urine on neonatal growth and reproduction. Anim. Behav. 20, 499-506.

Kaneko, N., Debski, E.A., Wilson, M.C. \& Whitten, W.K. (1980) Puberty acceleration in mice. Evidence 
that the vomeronasal organ is a receptor for the primer pheromone in male mouse urine. Biol. Reprod. 22, 873-878.

Keverne, E.B. (1979) The dual olfactory projections and their significance for behaviour. In Chemical Ecology: Odour Communication in Animals, pp. 75-85. Ed. F. J. Ritter. Elsevier, Amsterdam.

Milligan, S.R. (1980) Pheromones and rodent reproductive physiology. Symp. zool. Soc. Lond. 45, 251276.

Ojeda, S.R., Advis, J.P. \& Andrews, W.W. (1980) Neuroendocrine control of the onset of puberty in the rat. Fedn Proc. Fedn Am. Socs exp. Biol. 39, 2365-2371.

Reynolds, J. \& Keverne, E.B. (1979) Accessory olfactory system and its role in pheromonally mediated suppression of oestrus in grouped mice. J. Reprod. Fert. 57, 31-35.

Ryan, K.D. \& Schwartz, N.B. (1980) Changes in serum hormone levels associated with male induced ovulation in group-housed adult female mice. Endocrinology 106, 959-966.

Vandenbergh, J.G. (1969) Male odour accelerates female sexual maturation in mice. Endocrinology 84, 658660.

Vandenbergh, J.G. (1973) Acceleration and inhibition of puberty in female mice by pheromones. J. Reprod. Fert., Suppl. 19, 411-419.

Wilson, M.C., Beamer, W.G. \& Whitten, W.K. (1980) Puberty acceleration in mice. I. Dose response effects and lack of critical time following exposure to male mouse urine. Biol. Reprod. 22, 864-872.

Wuttke, W., Dohler, K.D. \& Gelato, M. (1976) Maturation of positive feedback action of oestradiol and its inhibition by prolactin in female rats. $J$. Endocr. 68, 391-396.

Wuttke, W., Honma, K., Lamberts, R. \& Hohn, K.G. (1980) The role of monoamines in female puberty. Fedn Proc. Fedn Am. Socs exp. Biol. 39, 2378-2383.

Received 26 October 1981 